\title{
THERMAL ANALYSIS AND EXPERIMENTAL VERIFICATION FOR DIII-D OHMIC HEATING COIL REPAIR
}

\author{
C.B. BAXI and P.M. ANDERSON
}

This is a preprint of a paper to be presented at the 18th IEEE/NPSS Symposium on Fusion Engineering, October 25-29, 1999, in Albuquerque, New Mexico, and to be published in the Proceedings.

\author{
Work supported by \\ the U.S. Department of Energy \\ under Contract No. DE-AC03-99ER54463
}

GA PROJECT 30033

NOVEMBER 1999 


\section{DISCLAIMER}

This report was prepared as an account of work sponsored by an agency of the United States Government. Neither the United States Government nor any agency thereof, nor any of their employees, make any warranty, express or implied, or assumes any legal liability or responsibility for the accuracy, completeness, or usefulness of any information, apparatus, product, or process disclosed, or represents that its use would not infringe privately owned rights. Reference herein to any specific commercial product, process, or service by trade name, trademark, manufacturer, or otherwise does not necessarily constitute or imply its endorsement, recommendation, or favoring by the United States Government or any agency thereof. The views and opinions of authors expressed herein do not necessarily state or reflect those of the United States Government or any agency thereof. 


\section{DISCLAIMER}

Portions of this document may be illegible in electronic image products. Images are produced from the best available original document. 


\title{
Thermal Analysis and Experimental Verification for DIII-D Ohmic Heating Coil Repair*
}

\author{
C.B. Baxi and P.M. Anderson \\ General Atomics, P.O. Box 85608, San Diego, California $92186-5608$
}

\begin{abstract}
The DIII-D ohmic heating $(\mathrm{OH})$ coil solenoid consists of two parallel windings of 48 turns cooled by water. Each winding is made up of four parallel conductors. Desired thermal capability of the coil is $80 \mathrm{MJ}$ at a repetition rate of 10 minutes. One of the conductors started leaking water in July 1995. Between July 1995 and December 1997 the coil was operated at a reduced thermal load using one winding. An experiment followed by analysis was undertaken to determine if the $\mathrm{OH}$-coil could be operated at full capacity by relying on conduction heat transfer to the neighboring cooled conductors without actively cooling the leaking segment. The analysis took into consideration the transient energy equations, including the effect of conduction between neighboring conductors. An experiment was performed on the undamaged coil winding to determine the thermal conductance between neighboring conductors. The experiment consisted of passing hot water through cooling channels of two conductors and cold water through the cooling channels of the remaining two conductors of the same winding. The flow rate, inlet and outlet temperatures from each circuit were measured during the transient. From the experimental data and analysis, an average thermal conductance between the conductors was determined to be about $800 \mathrm{~W} / \mathrm{m}^{2}-\mathrm{C}$. Using the experimentally determined value of the thermal conductance, an analysis was performed on a coil winding consisting of two uncooled conductors and two cooled conductors. Results show that it is possible to operate the full OH-coil to the desired thermal load of $80 \mathrm{MJ}$ per pulse without actively cooling the damaged conductor. During an operational test, the coil was instrumented to measure the outlet water temperature from the conductors before operating it at full current capacity. The coil was operated at $80 \%$ energy level and outlet coolant temperatures were compared with analytical results. The comparison between analysis and measured coolant outlet temperatures was within $10 \%$. This gives us sufficient confidence to operate the OH-coil at full capability in the future. It should be noted that the coil can be operated at a capacity of $180 \mathrm{MJ}$ if adequate time is allowed between cycles ( $\sim 30$ minutes) for the coil to cool completely. Forces $(\mathrm{I} \times \mathrm{B})$ within the repaired conductor limit allowable current. For short pulses $(<5 \mathrm{~s})$ this limits the thermal input to less than $180 \mathrm{MJ}$.
\end{abstract}

\section{INTRODUCTION}

The DIII-D tokamak was built in 1986 and uses the ohmic heating coil previously fabricated for the Doublet III in 1978. One of the conductors in the ohmic heating coil developed a leak in July 1995. Examination of the cooling circuit indicated that in addition to the cracked conductor two tubes connecting the outlet flow from the conductors to the exit manifold were also damaged during abrasive cleaning.

The DIII-D ohmic heating $(\mathrm{OH})$ coil solenoid consists of two parallel windings of 48 turns each, cooled by water flow through the conductors. Each winding is made up of two electrically parallel conductors about $200 \mathrm{~m}$ in length with four parallel coolant paths. Figure 1 shows the estimated flows in conductors after repairing the inlet and exit connections and plugging the cracked conductor. The coil is normally operated such that an energy input of $80 \mathrm{MJ}$ occurs nearly instantaneously ( $10 \mathrm{~s})$ compared to the cooling time of $600 \mathrm{~s}$ between plasma shots. The maximum allowable coil temperature is limited to $70^{\circ} \mathrm{C}$, which is a limit on the epoxy temperature. The normal cooling water flow rate per conductor is $9.5 \mathrm{\ell} / \mathrm{min}$ ( $2.5 \mathrm{gpm}$ ). The purpose of this work was to investigate cooling schemes, which will allow the $\mathrm{OH}-$ coil to be operated at the desired energy rating.

\section{FORMULATION}

Consider a conductor of area $A_{s}$ and length $L$ cooled by coolant channel of Area $A_{w}$ (Fig. 2). Following relations can be written for transient temperatures $T_{w}$ and $T_{s}$ of the coolant and the conductor (see nomenclature):

$$
\begin{aligned}
& (\rho \mathrm{CpA})_{\mathrm{s}} \frac{\partial \mathrm{T}_{\mathrm{s}}}{\partial \mathrm{t}}=\mathrm{q}^{\prime \prime \prime} \mathrm{A}_{\mathrm{s}}-\mathrm{hP}\left(\mathrm{T}_{\mathrm{s}}-\mathrm{T}_{\mathrm{w}}\right) \\
& +\mathrm{KW}\left(2 \mathrm{~T}_{\mathrm{s}}-\mathrm{T}_{\mathrm{n} 1}-\mathrm{T}_{\mathrm{n} 2}\right)+\mathrm{k} \frac{\partial^{2} \mathrm{~T}_{\mathrm{s}}}{\partial \mathrm{X}^{2}} \\
& (\rho \mathrm{CpA})_{\mathrm{w}} \frac{\partial \mathrm{T}_{\mathrm{w}}}{\partial \mathrm{t}}=-(\rho \mathrm{CpA})_{\mathrm{w}} \mathrm{V} \frac{\partial \mathrm{T}_{\mathrm{w}}}{\partial \mathrm{X}} \\
& +\mathrm{hP}\left(\mathrm{T}_{\mathrm{s}}-\mathrm{T}_{\mathrm{w}}\right)
\end{aligned}
$$

The above formulation accounts for the axial conduction in the conductor but ignores it in the coolant. The radial temperature distribution in the copper is neglected because the Biot number, $\mathrm{Bi}=\mathrm{h} \delta_{\mathrm{cu}} / \mathrm{k}_{\mathrm{cu}}=0.3<1$.

Further, relations for the volumetric heating $\mathrm{q}^{\prime \prime \prime}$ and the heat transfer coefficient $h$ are:

$$
\begin{aligned}
& \text { Heat Generation per unit volume: } \\
& \mathrm{q}^{\prime \prime \prime}=\left(\mathrm{I} / \mathrm{A}_{\mathrm{s}}\right)^{2} \sigma_{\mathrm{o}}\left[1.0+0.04\left(\mathrm{~T}_{\mathrm{s}}-20\right)\right] \\
& \mathrm{q}^{\prime \prime \prime}=0.0 \text { for } \mathrm{t}>\mathrm{tp}
\end{aligned}
$$

Heat Transfer coefficient:

$$
\mathrm{h}=\mathrm{Nuk}_{\mathrm{w}} / \mathrm{d}
$$

\footnotetext{
*Work supported by U.S. Department of Energy under Contract No. DE-AC03-99ER54463.
} 


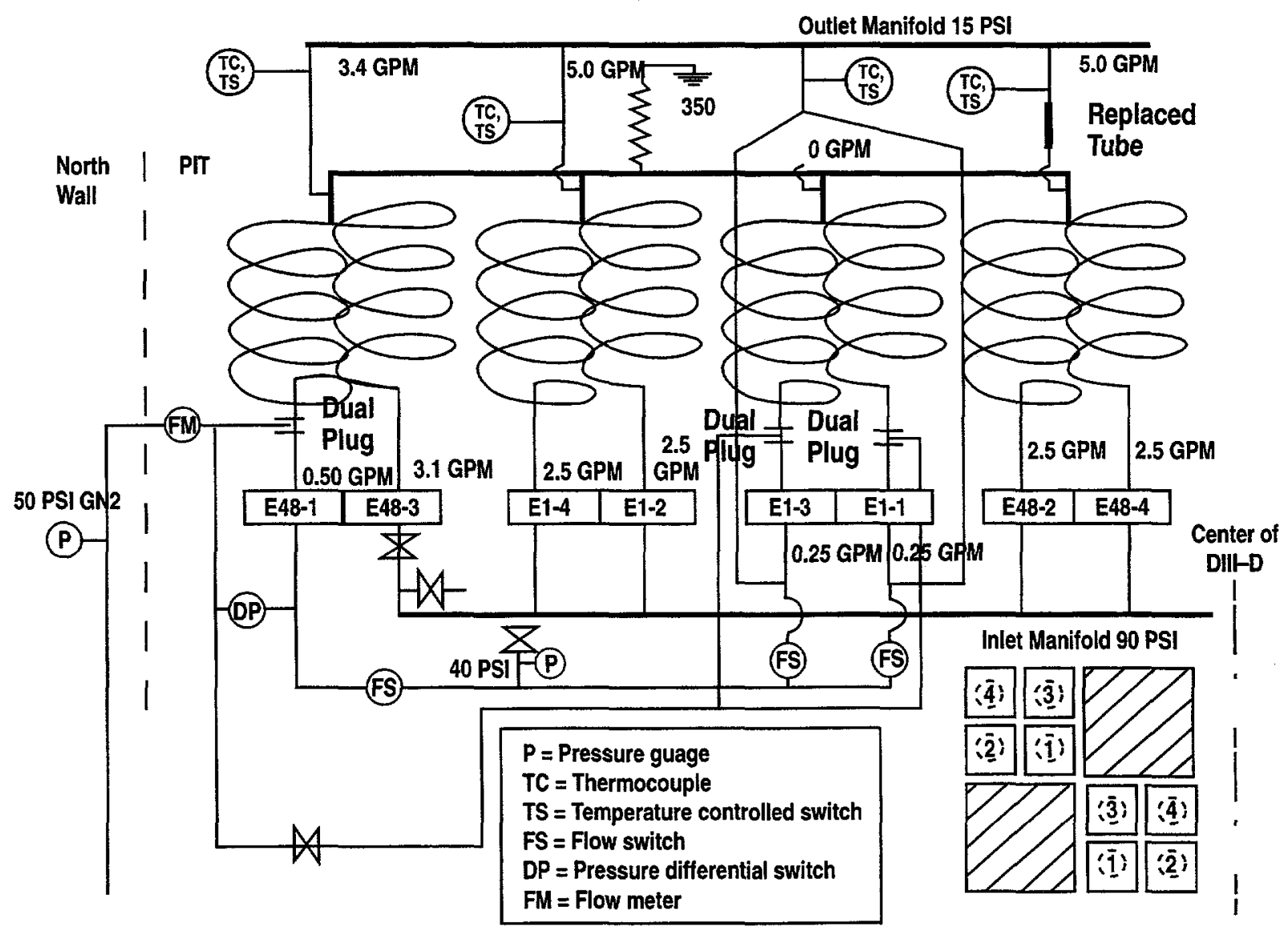

Fig. 1. Modified coolant flows for DIII-D OH-coil.

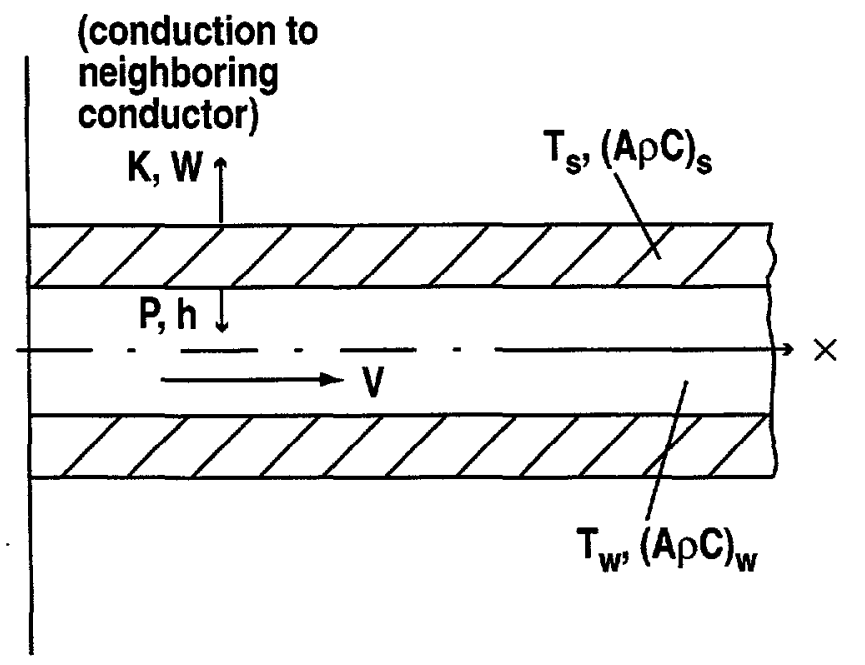

Fig. 2. Analysis Model.

where:

$\mathrm{Nu}=0.023(\mathrm{Re})^{0.8}(\mathrm{Pr})^{0.4}$ and

$\operatorname{Re}=$ Reynolds number $=\rho d V / \mu$

$\mathrm{Pr}=$ Prandtl number

Using these relations, a program was developed to perform this analysis. An implicit numerical scheme was used to solve the equations.

\section{THERMAL CONDUCTANCE}

One of the important variables required to solve the Eqs. (1) and (2), is the thermal contact conductance between the conductors. The conductors are welded to each other at intervals of $30 \mathrm{~cm}$ in the lead area (first $2 \mathrm{~m}$ length) and gaps between the conductors $(0.25 \mathrm{~mm})$ for the remaining length are filled with epoxy glass composite.

An experiment was performed with the undamaged coil bundle to determine the average thermal conductance. Using four neighboring leads like Fig. 1, the inlet temperature of water to two of the conductors was maintained at about $51^{\circ} \mathrm{C}$ while inlet temperature to other two other conductors was kept at about $21^{\circ} \mathrm{C}$. There was no electrical current flowing in the conductors. Outlet temperatures were monitored as a function of time. The experiment was run till steady state was achieved in about 30 minutes. The outlet temperature from hot and cold channels was always equal during the transient. The steadystate temperature was slightly less than the mixed mean temperature. These conditions were used in the program described above and the conductance in-between the conductors varied till agreement between experiment and analysis was obtained. Since the measured steady-state temperature was less than the mixed mean temperature, it was concluded that some heat loss was occurring to the neighboring winding. The analysis of the experiment shows that the value of average thermal conductance between the 
conductors is $800 \mathrm{~W} / \mathrm{m}^{2}-\mathrm{C}$ and the conductance in-between the windings is $5 \mathrm{~W} / \mathrm{m}^{2}-\mathrm{C}$ (Fig. 3). The experimentally determined value compares with the estimated value of the thermal conductance based on thickness and thermal conductivity of the epoxy $(\mathrm{K}=\delta / \mathrm{k})$ within $25 \%$.

\section{PERFORMANCE VERIFICATION}

The cooling system was originally designed for a parallel water flow rate of about $9.5 \mathrm{l} / \mathrm{min}(2.5 \mathrm{gpm})$ through each conductor. However, due to the leaking conductor and leaks in the outlet tubes, extensive repairs were undertaken [1]. Even after the repairs, normal flow of $2.5 \mathrm{gpm}$ parallel flow in each conductor could not be restored. Also, one difficulty still remained to be overcome. The first $2 \mathrm{~m}$ length of the conductors is thermally isolated from each other. Analysis shows that temperature of the uncooled conductor will ratchet up to $144^{\circ} \mathrm{C}$, in this part. Hence, a separate cooling scheme to cool this part of the conductor by low pressure water was devised. The worst flow condition consisted of normal parallel flow of $9.5 \mathrm{l} / \mathrm{s}$ in two of the four conductors in a winding and a flow rate of $0.95 \mathrm{l} / \mathrm{min}(0.25 \mathrm{gpm})$ in the leads only of the other two conductors. Four conductors depicted on the RHS in Fig. 1 represent the worst flow conditions after the $\mathrm{OH}$-coil cooling system was modified.

After the repairs, the coil was operated at $80 \%$ of the desired energy input of $80 \mathrm{MJ}$ and the exit water temperature of the worst cooled winding was compared to the analysis (Fig. 4). This analysis took into consideration conductance in between the conductors and in-between the windings. The excellent comparison gives us enough confidence to operate the $\mathrm{OH}$-coil at full capacity of $80 \mathrm{MJ}$ per pulse. Figure 5 shows the maximum temperature of the coil if it is operated now at $80 \mathrm{MJ}$ energy input per pulse at a rep rate of $600 \mathrm{~s}$. The maximum calculated temperature is below the limit of $70^{\circ} \mathrm{C}$.

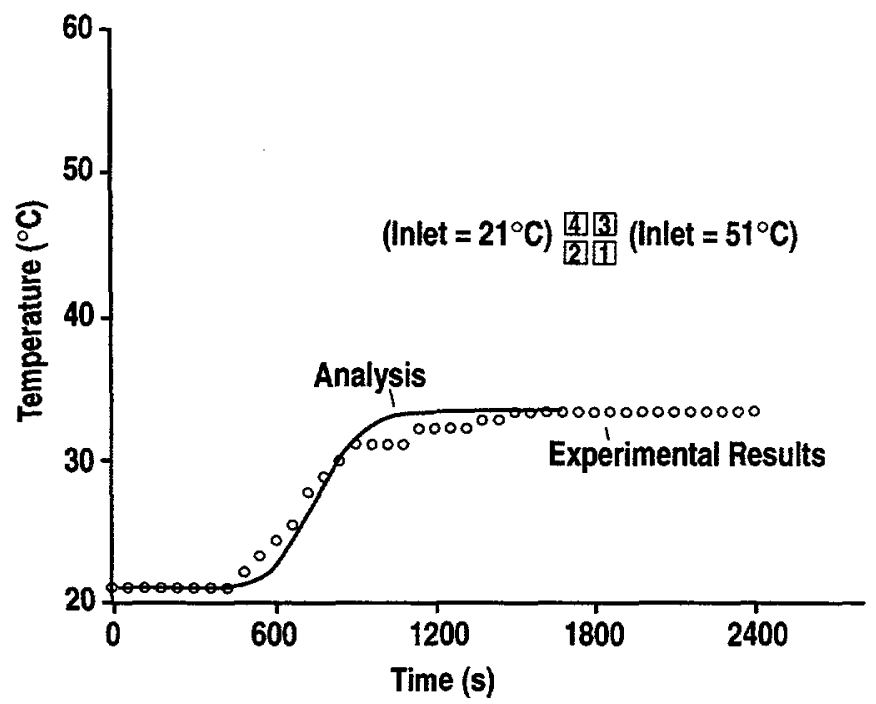

Fig. 3. Comparisons of exit temperatures between experiment and analysis (conductance in between conductors $=800.0 \mathrm{~W} / \mathrm{m}^{2}-\mathrm{C}$ and between bundles $=5.0 \mathrm{~W} / \mathrm{m}^{2}-\mathrm{C}$ ).
Ref. 1.

Details of mechanical repair work done is described in

\section{CONCLUSIONS}

1. The average thermal conductance between the conductors of DIII-D ohmic heating coil is $800 \mathrm{~W} / \mathrm{m}^{2}-\mathrm{C}$.

2. It is possible to operate the ohmic heating coil for with desired energy input of $80 \mathrm{MJ}$ with a rep rate of $10 \mathrm{~min}$. without cooling the leaking conductor.

3. The first $2 \mathrm{~m}$ lengths of the conductors are thermally isolated from each other. A low pressure water circuit at a $10 \%$ flow rate cools this length for the leaking conductor.

4. Performance of the repaired coil checks out with the analysis model.

\section{NOMENCLATURE}

$A=$ Area $; m^{2}$

$\mathrm{Bi}=\mathrm{Biot}$ number $=\mathrm{h} \delta_{\mathrm{S}} / \mathrm{K}_{\mathrm{s}}$

$\mathrm{Cp}=$ specific heat, $\mathrm{J} / \mathrm{kg}-\mathrm{C}$

$\mathrm{d}=$ diameter of coolant channel; $\mathrm{m}$

$\mathrm{h}=$ heat transfer coefficient; $\mathrm{W} / \mathrm{m}^{2}-\mathrm{C}$

$I=$ current; Amp

$\mathrm{k}=$ thermal conductivity, $\mathrm{W} / \mathrm{m}-\mathrm{C}$

$\mathrm{K}=$ thermal conductance between neighboring turns, $\mathrm{W} / \mathrm{m}^{2}-\mathrm{C}$

$\mathrm{Nu}=$ Nusselt number: $\mathrm{hd} / \mathrm{K}_{\mathrm{w}}$

$\mathrm{P}=$ cooling channel perimeter; $\mathrm{m}$

$\mathrm{q}^{\prime \prime \prime}=$ heat generation rate; $\mathrm{W} / \mathrm{m}^{3}$

$\mathrm{t}=$ time; $\mathrm{s}$

tp = pulse length; $s$

$\mathrm{T}=$ temperature $;{ }^{\circ} \mathrm{C}$

$\mathrm{V}=$ flow velocity $; \mathrm{m} / \mathrm{s}$

$\mathrm{W}=$ width of contact between neighboring turns; $\mathrm{m}$

$\mathrm{X}=$ axial distance; $\mathrm{m}$

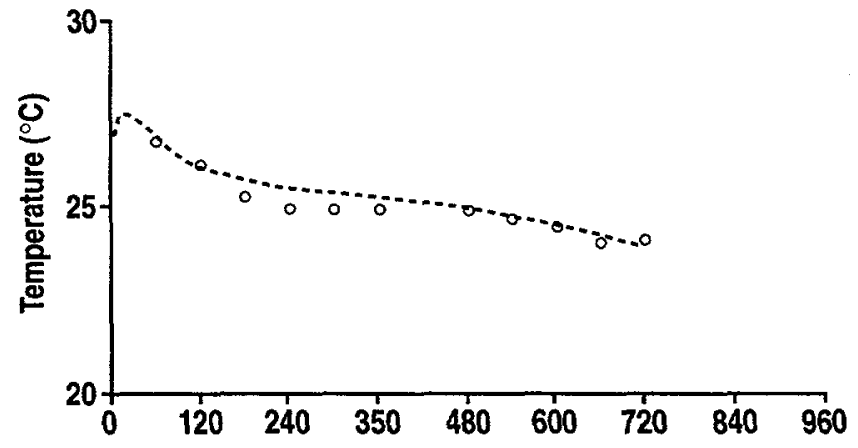

Fig. 4. Comparison between calculated and measured outlet water temperatures from DIII-D OH-coil. 


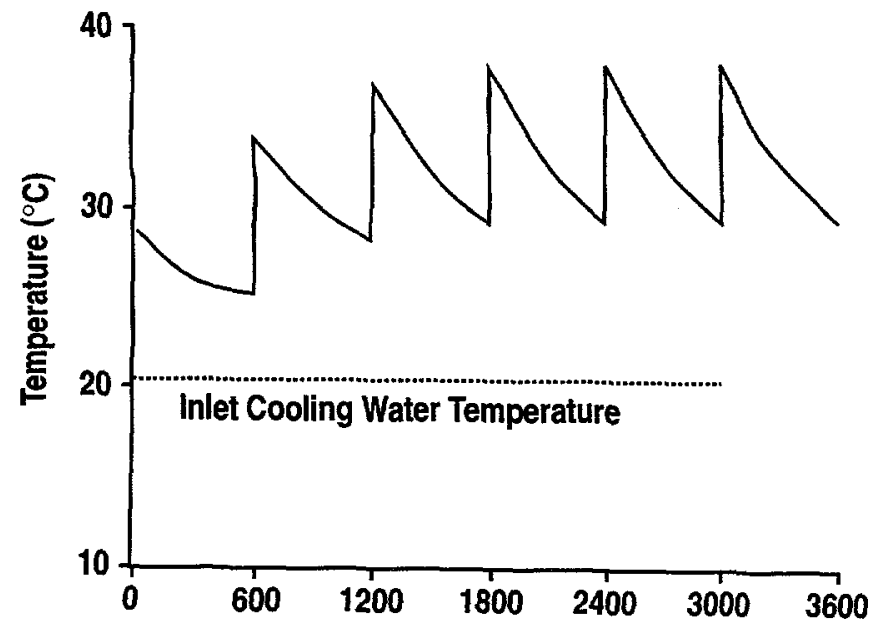

Fig. 5. Peak temperatures in the uncooled conductor during subsequent pulses. $\sigma_{0}=$ resistivity at $20^{\circ} \mathrm{C} ; \mathrm{ohm}-\mathrm{m}$

$\alpha=$ resistance coefficient: $1{ }^{\circ} \mathrm{C}$

$\mu=$ viscosity; $\mathrm{Pa}-\mathrm{s}$

$\rho=$ density; $\mathrm{kg} / \mathrm{m}^{3}$

$\delta=$ thickness; $m$

Subscripts

$\mathrm{s}, \mathrm{cu}=$ copper

$w=$ water

$\mathrm{n} 1, \mathrm{n} 2=$ neighboring channels

\section{REFERENCE}

[1] P.M. Anderson, et al., "Restoration of the DIII-D Solenoid," Proc. of the 17th Symp. on Fusion Engineering, San Diego, California, 1997, Vol. 2, 669 (1998). 